reviews

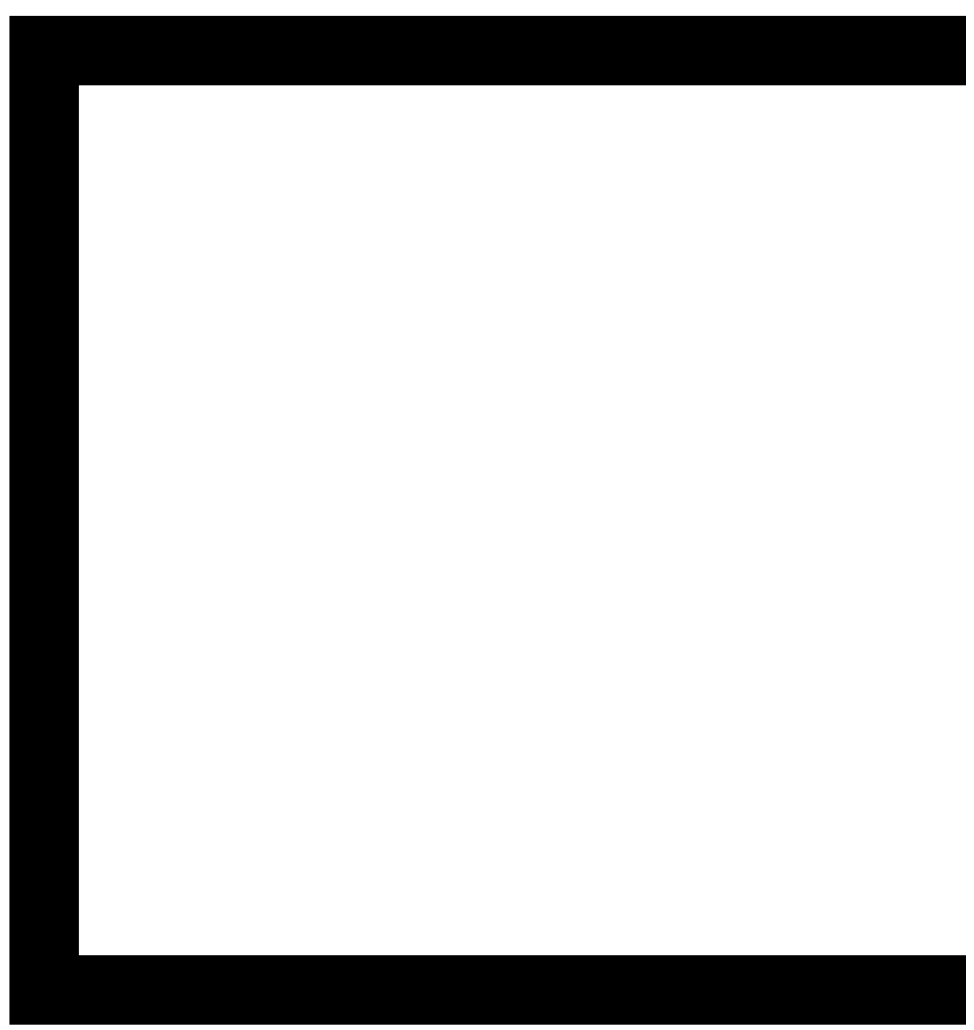




\section{affectively addressing cultural studies}

MELISSA GREGG
Cultural Studies’ Affective Voices
Palgrave Macmillan, New York, 2006
ISBN 1403999023
RRP $\$ 144.00(\mathrm{hb})$

Employing in her own scholarship the positive affects that generate the 'solidarity, commitment and hope' Gregg claims for cultural studies as a discipline, Cultural Studies' Affective Voices stages far more than a series of encounters with familiar voices. Gregg's monograph enacts an ethical relation to others marked by generosity, hospitality, empathy and intellectual rigour that not only places her own powerfully affective voice within cultural studies' debates and dialogues, but also isolates the productive potential of what it might mean to emotionally invest in academic work despite the insidious technologies inherent in neoliberalism. ${ }^{1}$ Hers is a critical and political intervention that recognises the significance of an affective critical address that invites an ethical response both within and beyond the academy. Gregg's 'different kind of inventory' of cultural studies is compelling because of her recognition of the 'ontological dimension' (2) of cultural studies' innovative practices through which she details the social pleasures involved in scholarly work. Her attentiveness to the valuable techniques and strategies employed by key figures in cultural studies not only does the work of constituting an alternative disciplinary history, but also provides a toolbox from which younger generations can draw so as to imagine a hopeful future.

Carefully mapping 'affect's relationship to cultural studies' political ambitions' (4), Gregg's account begins with her concern that while she was completing her manuscript, James Donald and Elspeth Probyn concurred in a cultural studies plenary that the practice of disciplinary reflexivity had become somewhat tedious. 
Gregg is quick to capture the irony of this such as Eleanor Kaufman. ${ }^{2}$ Carefully structuring public agreement, attending to the significant her confession to readers, she claims that she accounts each of these scholars has made to writes with all 'biases and assumptions' (3) of disciplinary debates that have had important the next generation of cultural studies scholars, effects within and beyond cultural studies. In offering her reader an 'overdue assessment of addition to reframing this debate, Gregg's the continued hope' (3) to be drawn from the anecdote is employed precisely because of her discipline's dominant traditions. Gregg also realisation that 'something fundamental has considers what it might mean for academics to been missing from existing accounts of cultural position the university as the site of their onstudies'. (1) Identifying this absence as 'cultural going investment as scholars. Her account is studies' particular investment and commitment particularly refreshing and timely because she to scholarly practice' (1), Gregg's monograph acknowledges the effects of neoliberal technofocuses on cultural studies scholars' vocation logies operating within current work cultures and the methods some scholars employ to (including the academy); however, by focusing effectively communicate their analyses so that on innovative strategies and practices, Gregg's their work might have a greater and wider account purposively generates the positive affect political impact. Most importantly, Gregg fore- she holds so dear in the writing of others.

grounds techniques and develops strategies and Starting with Richard Hoggart-founder of thinking that can intervene in conservative the Birmingham Centre for Contemporary Culregimes and practices. tural Studies-Gregg examines the discourse of

Focusing on intellectual contributions from Richard Hoggart, Stuart Hall, Lawrence Grossberg, Andrew Ross and Meaghan Morris, Gregg provides her reader with a nuanced critical history that prioritises the political and refuses a division between theory and practice. She attends to the role a writer's voice has in generating a reader's interest-particularly as this plays out in the academy-discussing the effect of an affective address that inspires reader to become writer, thus participating in current debates. Detailing the benefits of, and employing, Morris's 'sympathetic reading', which requires a reader to 'put one's own biases' aside, empathy that figures in Hoggart's descriptions and analyses of working class life. Situating her reading within contemporary debates about the role of empathy in representation, Gregg's concern is whether 'scholarly discourse can change to accommodate a more compassionate regard for its subjects of analysis'. (30) Detailing the ways in which Hoggart's voice acts as LaCapra's 'counterforce to numbing' in which we are encouraged to experience active rather than passive empathy, or to take action rather than use the other as means of returning to the self, Gregg explains how Hoggart subverts de Gregg encourages the practice of 'intellectual working-class life warranted less consideration hospitality' (15) advocated by philosophers than bourgeois ideals. By focusing on critical 
literacy and employing thick description-to mention just two of the techniques that Gregg identifies-Hoggart effectively communicated his work across class boundaries, shifting the expectation that academic discourse should objectify the other in order to develop an 'accurate' account of working class life.

It makes sense that Gregg moves her focus from Hoggart to Stuart Hall given Hoggart's invitation to Hall to join the Centre for Contemporary Cultural Studies in Birmingham. In 1968, Hall was to become director of CCCS. Recognising the difficulty in presenting a new account of Hall's contribution to cultural studies given his popularity, Gregg focuses on the importance of Hall's 'conjuntural politics', pointing to three theoretical insights he uses as part of this strategy: arbitrary closure, articulation, and testing theory. While arbitrary closure requires that we pause, so as to formulate and clarify the position from which we choose to speak, articulation requires that we bring together 'the components which constitute society' allowing for 'holes and openings for change' that might otherwise go unnoticed.

(60) With each intervention, Hall is keen to test new frameworks, employing arbitrary closure, and his practice of articulation keeps his theoretical insights relevant. Gregg provides examples of Hall's conjuntural focus, examining the impact of Policing the Crisis (1978) wherein Hall and his colleagues examined the sociopolitical conditions in which moral panic arose after a young Irish worker was mugged and robbed by three youths from different ethnic backgrounds, each of whom received prison sentences of ten or twenty years. Producing an alternative account of the context from which moral panic about the incident emerged, Hall and his colleagues examined the increasing influence of American culture, including the history of the word 'mugging', on British society. Gregg also discusses Hall's intervention into Thatcherism and his critique of the Left's failure to effectively intervene into this political regime in light of his conjunctural approach, which Gregg argues, 'provides a means to distinguish how people differ from the abstract formulations at the heart of government'. (67) This chapter closes with Hall's turn to identity politics-a turn that Gregg employs to discuss notions of the human and inhuman in a post 9/11 political climate. Deploying Hall's methodology, Gregg demonstrates the ways in which his affective address and conjunctural focus have contributed to the production of alternative narratives about seemingly familiar events and practices.

Making a trans-Atlantic connection between Hall's conjunctural politics and Lawrence Grossberg's adoption of a 'messianic tone' so as to combat the New Right's colonisation of the 'mood', 'imagination' and 'hopes of a citizenry', Gregg investigates the 'scriptural' dimension of Grossberg's scholarly work. (82) Grossberg studied and worked with Hall at the CCCS in Birmingham, and Gregg points to the major influence this experience had on Grossberg's version of cultural studies within an American context. Gregg discusses the affective dimension of Grossberg's work on popular music and youth culture, pointing to the breadth of his 
theoretical influences from Freud to Deleuze and assessing his commitment to both capturing the corporeality of affect and employing affective address to political ends, a commitment that Gregg also echoes in her own work. Developing the concept of a 'mattering map', which describes the location, intensity and absorption people experience in their everyday lives, Grossberg shifts the 'epistemological goals' attached to accounts that might devalue rock music, or other kinds of popular genres and cultural events. (88) Gregg's insightful representation of Grossberg's scholarship emphasises the significant role he has played in the development of cultural studies as a discipline given that popular culture 'acts as a recompense for the dissatisfactions and mundanity of daily life' as well as acting as a powerful political force for 'big government to make use of it for their own objectives'. (92) Keeping true to her declaration that she speaks for the next generation, Gregg ends this chapter pondering the limits of a patronage model (of address, supervision and mentoring) on a generation of graduate students whose working lives are measured by the impermanency and instability offered by the casual contract in neoliberal times.

It is appropriate then that Gregg focuses her attention on the scholarship of Andrew Ross whose focus is labour (including sweatshop labour), workforce cultures, business and technology, drawing links between the university and capitalist corporations. Gregg's interest is in Ross's focus on the 'human side of economic change' (107) and she draws links between Grossberg's observations that private life figures more prominently than 'public political expression in the United States'. (110) Gregg selects telling examples from Ross's work, including Disney's community-oriented housing estate known as Celebration, which employed its staff at the base-level sweatshops in China that offer Western investors high, quick returns, and also the phenomenon of 'no collar workers'-a product of the growth in information and communication industries. Gregg's analysis demonstrates Ross's concern to reveal the human and ethical dimensions of economic growth under capitalism.

Of particular interest in this chapter are relations between new technologies and the supposed flexibility of working anywhere, anytime, at any location and subsequent exploitation of boundaries between work and leisure. In addition, Gregg discusses Ross's analogy of creative workers 'who have rationalised their diminished status in society through a system which gauges artistic and political integrity by the lack of recognition and financial compensation granted by the wider culture' (121), comparing artists and academics who are positioned by the ways in which capital is structured, and the academy in turn, to share a similar ethos built on anticipated 'future career rewards'. (121) Gregg uses Ross's analyses of the exploited worker within a neoliberal market to produce an insightful account that not only requests that academics question their own investment in scholarly life, but also that cultural studies, as a discipline, question its continuing relationship to the university 'name' that is not so different to any other brand. Although Ross considers his work to have 
moved away from cultural studies' concerns, nationality and globalisation, and Australian Gregg's study demonstrates why this kind of and Asian-Pacific popular culture, have transscholarship is perhaps more important now formed scholarly thinking because of her belief than ever before. that 'academic practice has ethical obligations,

Concluding her monograph by examining the power of Meaghan Morris's affective address, munity'. (150)

Gregg brings together examples from Morris's

Cultural Studies' Affective Voices offers a scholarship that demonstrate the effects of her nuanced genealogy of scholarly contributions characteristic frankness and daring in the pro- from key voices that have influenced the forduction of an ongoing critique of the kinds of mation and development of cultural studies as knowledge generated in cultural studies. Em- a discipline, while arguing for the vitality of an ploying anecdote, humour, and remaining vigi- affective address that speaks to a wider audience lant to whether 'the certainty underpinning so as to effect change. Gregg's own scholarship earlier models of intellectual practice is no enacts the 'optimistic, inspiring and mobilising longer sustainable' (140), Gregg discusses the functions' (159) she suggests are crucial for culways in which Morris's scholarship continues to tural studies to avoid complacency, remain rel'pack a punch', thus transforming discourse. evant, and to intervene in wider socio-political Gregg's analysis demonstrates the significance regimes and structures. Gregg's vision is comof Morris's earlier career as a freelance writer, plemented by Sydney-based artist Jane Simon's film critic and intellectual in creating formative photo on the cover, titled Ajar (2005). The open relations between critic and the public. Only in book, unhinged bookcase and play of light more recent times has Morris joined ranks with from the window's reflection refer to Simon's the academy, taking up posts in both Hong interest in domestic detail and small forgotten Kong and Sydney. While her criticism is often spaces. So, too, does Gregg provide for her personal in tone, Morris believes: reader the details, subtleties and nuances of an account that might otherwise be forgotten.

To discredit a voice is something very different from displacing an analysis which has become outdated, or revising a strategy which no longer serves its purpose. (Morris cited by Gregg, 138.) ${ }^{3}$

Gregg points to the ways in which Morris's voice remains enthusiastic for 'reforms to scholarly discourse' (152) and in which her diverse contributions to film and media, culCRISTYN DAVIES works in research with the Narrative, Discourse and Pedagogy research concentration at the University of Western Sydney. She is particularly interested in relations between writing and affect as they intersect with performance and performativity. <c.m.davies@uws.edu.au> tural studies' history, constructions of gender, 
1. Gregg's extension of generosity enacts the kinds of practices discussed by Rosalyn Diprose in Corporeal Generosity: On Giving with Nietzsche, Merleau-Ponty, and Levinas, SUNY, New York, 2002.

2. The kind of hospitality both Kaufman and Gregg advocate and practise is also enacted by Jacques Derrida and Anne Dufourmantelle in Of Hospitality, trans. Rachel Bowlby, Stanford University Press, Stanford, 2000

3. Meaghan Morris, 'Banality in Cultural Studies', in John Storey (ed.), What is Cultural Studies? A Reader. Arnold, London, 1996, p. 160. 